\title{
A FILOSOFIA DEPOIS DO FIM DA FILOSOFIA
}

\author{
PHILOSOPHY AS CULTURAL POLITICS - PHILOSOPHICAL PAPERS, VOL. 4. \\ de Richard Rorty. Cambridge: Cambridge University Press, 2007.
}

JOAQUIM TOLEDO JR.

[1] Agradeço aos comentários e sugestões de Caetano Ernesto Plastino, Marcos Nobre e Tiago Mesquita.
[2] In: Rorty, Richard M. (org.). The linguistic turn - Essays in philosophical method. Chicago: University of Chicago Press, 1992 [1967].
A convicção realista de que deve haver uma autoridade não-humana à qual os homens podem recorrertem sido, porlongo tempo, entremeada ao senso comum do Ocidente. É uma convicção comum a Sócrates e Lutero, a cientistas naturais ateus que dizem amar a verdade e fundamentalistas que dizem amar a Cristo. Acho que seria uma boa idéia reinventar a rede de crenças e desejos compartilhados que compõem a cultura ocidental com o objetivo de nos livrarmos dessa convicção. Richard Rorty, Philosophical papers, vol. 4

No intervalo de quarenta anos entre a publicação de "Metaphilosophical difficulties in analytic philosophy" ${ }^{2}$, o hoje clássico artigo que abre a coletânea The linguistic turn, e do quarto volume dos seus Philosophical papers, Richard Rorty (1931-2007) consolidou-se como uma das figuras centrais do pragmatismo norte-americano. Formado nos rigores da tradição analítica e autoproclamado herdeiro de John Dewey e William James, Rorty faz convergir duas tradições concorrentes da filosofia contemporânea: de um lado, a linha analítico-lingüística que sai de Fregee Russel e passa pelo círculo de Viena e pelo primeiro Wittgenstein; de outro, a linha historicista de inspiração hegeliana, que inclui Heidegger e os próprios James e Dewey, assim como o "híbrido" Wittgenstein (analítico, mas não positivista) das Investigações filosóficas. Rorty tem despertado discussões não apenas entre filósofos da linhagem mais tradicional, e técnica, da filosofia analítica, mas também entre autores como Jürgen Habermas e Charles Taylor, que propõem uma vinculação entre o pensamento filosófico e as ciências humanas. Suas propostas de revisão radical — ou, antes, abandono - de conceitos centrais para a tradição epistemológica como mente, verdade e sentido e as conseqüências que uma tal posição pragmatista pode trazer para o debate político e cultural contemporâneo têm estimulado um amplo debate entre filósofos das mais diferentes orientações teóricas. 
As razões que levaram um promissor filósofo analítico a abandonar o projeto de fazer da filosofia uma atividade científica — capaz não apenas de identificar os problemas filosóficos fundamentais, mas também de, com o auxílio de um método rigorosamente estabelecido (a análise lingüística), resolvê-los - e a adotar uma visão da reflexão filosófica que a aproxima mais da história cultural ou de uma narrativa que procura contar a história das grandes metáforas que dominam os intelectuais de determinadaépoca podem ser reconstruídas, ainda que de forma simplificada, considerando a crítica ao projeto analítico elaborada no artigo de 1967 e o caminho que tomou sua obra nas décadas seguintes.

Para os filósofos da tradição analítica — de RudolfCarnap a Michael Dummett - a racionalidade da filosofia depende de uma definição de sua natureza e de seus métodos que não repouse em nenhuma tese filosófica substantiva, assim como de uma definição de critérios de sucesso que permitam o acordo racional em torno de suas teses. A analogia evidente é com uma certa imagem da atividade científica: baseados em relatos de observação e apoiados em um método racional, os enunciados científicos teriam, idealmente, uma força de persuasão que força o reconhecimento de sua verdade por qualquer indivíduo igualmente racional. O fato, porém, de a tradição analítica ainda não ter sido capaz de atingir um consenso a respeito nem mesmo desses dois pontos fundamentais (natureza da disciplina e método apropriado) - que poderíamos chamar, com Rorty, de metafilosóficos, dado que tratam não de questões filosóficas, mas da própria filosofia - força a uma revisão do projeto analítico, que não pode se basear exclusivamente em uma crítica interna segundo o mesmo procedimento analítico. Esse tipo de revisão, já esboçado no artigo de 1967 ,é retomado com maior fôlego em Afilosofia e o espelho da natureza e consiste em identificare desconstruir as metáforas e imagens que jazem sob as posições filosóficas de autores e suas épocas. Em vez de perseguir supostos "pseudoproblemas" filosóficos e dissolvê-los com a análise lingüística, a filosofia deveria cuidar de revelaros pressupostos por trás dos vocabulários em que tais problemas estão formulados. Noções centrais da epistemologia como "verdade" e "sentido", por exemplo, estariam menos à espera de um "esclarecimento analítico" - uma teoria definitiva sobre sua natureza — do que de um questionamento de sua relevância: "voltar a essas suposições e tornar claro que são opcionais seria 'terapêutico' da mesma forma como foi 'terapêutica' a dissolução original aplicada por Carnap aos problemas filosóficos tradicionais"3. Ao contrário da visão dos problemas filosóficos por trás do projeto logicista de Carnap, porém, que os considera fruto natural da relação cognitiva do homem com o mundo, para Rorty os problemas que ocupam a mente dos filósofos teriam origem em escolhas contingentes de vocabulários. A imagem do conhecimento como "representação da natureza" que teria assombrado grande
[3] Rorty, R.A filosofia e o espelho da natureza. Rio de Janeiro: Relume Dumará, 1995 [1979], p. 14. 
[4] Rorty, R. Consequences of pragmatism. Minneapolis: University of Minnesota Press, 1982, p.xiv.

[5] Rorty, R.A filosofia e o espelho da natureza, op. cit., p. 20. parte da filosofia moderna seria mais responsável pelos dilemas em torno de uma definitiva fundamentação do conhecimento ou de uma definição de "verdade" do que uma suposta dificuldade inerente a esses problemas.

Problemas filosóficos, diria Rorty, são criados, não descobertos. É principalmente devido ao caráter artificial das questões filosóficas artificial no sentido de serem o fruto de um momento histórico específico, não da natureza humana - que o projeto analítico acaba chegando a um beco sem saída.

Em Consequences of pragmatism, Rorty propõe distinguir entre Filosofia, assim com "efe" maiúsculo, efilosofia, com "efe" minúsculo. O primeiro termo faria referência àquela atividade que, do platonismo ao círculo de Viena - incluindo seus seguidores contemporâneos tem como objetivo determinar de uma vez por todas a natureza da Verdade, do Bem e da Beleza. O segundo termo, fruto da consciência crítica de que esses termos se ressignificam constantemente e têm lugar no interior de jogos de linguagem específicos, mas não fora deles, seria o nome daquela atividade que, como propôs Wilfrid Sellars, procura ver "como as coisas, no sentido mais abrangente do termo, se relacionam, no sentido mais abrangente do termo, umas com as outras" 4 . Fundamentalmente, isso significa abandonar a concepção cientificista da atividade filosófica proposta por parte significativa da filosofia moderna e ver a filosofia como um gênero cultural entre outros, interessada em desconstruir velhas imagens do mundo a respeito do conhecimento, da moral e da arte e propor outras, mais adequadas aos interesses do presente. O esforço por racionalizar a reflexão filosófica encontrou seu impulso sobretudo na disputa, no nascimento da modernidade, entre ciência e religião; mas já no século XIX, com o processo de secularização mais consolidado, o lugar do filósofo foi desafiado pelo surgimento de uma "nova cultura", a "cultura do homem de letras - um intelectual que escrevia poemas e romances e tratados políticos, e críticas de poemas, romances e tratados de outras pessoas" 5 . A transformação da filosofia em uma atividade especializada, científica, a teria afastado do resto da cultura e, por conseguinte, do público interessado.

Uma crítica dessa concepção moderna da atividade filosófica implica um questionamento do lugar ocupado pela filosofia e do papel do filósofo em uma cultura racionalizada e pluralista, na qual nem a ciência, nem a religião, nem a filosofia podem reivindicar lugar de destaque. Por se ver privado - ou liberado - da função de "tribunal de última instância da razão", Rorty sugere que o filósofo assuma o papel de articulador da cultura - inventando maneiras de "fazer as coisas se relacionarem" - ou de contribuinte no grande debate cultural a respeito de representações, valores e objetivos que suas sociedades 
devem assumir. Nesse sentido, o filósofo deveria deixar de ser um caçador de essências para tornar-se um praticante de "política cultural" (cultural politics).

A noção de política cultural, como elaborada por Rorty, envolve uma consideração crítica das práticas lingüísticas correntes e de sua pertinência em relação ao projeto de uma sociedade democrática e pluralista. Se existem ou não raças, por exemplo, é uma questão menos importante do que saber se o uso do termo contribui para a construção desse projeto. Nos casos em que a garantia de igualdade para todos os membros de uma sociedade, sem nenhuma forma de discriminação, está relacionada à maneira como descrevemos e classificamos os objetos de nossa experiência - elementos da natureza, seres humanos então entramos no campo da política cultural.

$\mathrm{Na}$ introdução de A filosofia e o espelho da natureza, Rorty diz que Dewey, embora menos "hábil" do que Wittgenstein e menos "cultivado" do que Heidegger, teria sido fundamental para a crítica da filosofia moderna ao elaborar suas polêmicas contra a tradição cartesianokantiana inspirado pela "visão de um novo tipo de sociedade

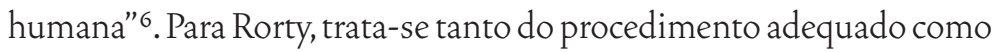
do papel correto da filosofia: a busca de uma sociedade mais igualitária, justa e livre deveria ser a motivação por trás da elaboração de concepções do homem, de sua capacidade de conhecer, de julgar e de se expressar, e não a estéril busca pela "verdade". A noção da filosofia como política cultural - tematizada e praticada - ocupa grande parte dos artigos reunidos no quarto volume dos seus Philosophical papers.

Organizado em três partes - "Religião e moralidade desde um ponto de vista pragmatista", "O lugar da filosofia na cultura" e "Temas atuais da filosofia analítica" - , Philosophy as cultural politics 7 reúne artigos que abrangem temas centrais da reflexão de Richard Rorty: a possibilidade - ou a relevância - de uma moral universalista, a função da filosofia e do filósofo em um mundo pós-Filosófico, assim como alguns temas próprios da tradição analítica, como as divergências em relação à interpretação da obra de Wittgenstein. Retomando o debate entre universalismo e relativismo moral em "Justice as a larger loyalty" ["Justiça como lealdade ampliada"], Rorty considera que uma distinção substantiva entre justiça e lealdade é uma herança dispensável da tradição kantiana de filosofia moral, mais ou menos como o seria a distinção entre "verdade" e "aparência" na tradição platônica:

O que Kant descreveria como o resultado do conflito entre obrigação moral e sentimento, ou entre razão e sentimento é, em uma avaliação nãokantiana da questão, um conflito entre um conjunto de lealdades e outro conjunto de lealdades. A idéia de uma obrigação moral universal de respeitar a dignidade humana é substituida pela idéia de uma lealdade a um grupo
[6] Ibidem, p. 28.

\footnotetext{
[7] Alguns dos ensaios reunidos nesta publicação apareceram em $E$ nsaios pragmatistas - sobresubjetividade e verdade (Ghiraldelli Jr., Paulo (org.). São Paulo:DP\&AEditora, 2006) eem Filsofia, racionalidade e democracia: os debates Rorty \& Habermas (José Crisóstomo de Souza (org.). São Paulo: Editora UNESP, 2005).
} 
[8] "Da maneira como vejo a filosofia contemporânea, a grande divisão [the great divide] é entre representacionistas, pessoas que acreditam que existe uma natureza intrínseca da realidade não-humana, que os humanos têm o dever de apreender, $e$ antirepresentacionistas" (p.134). muito amplo - a espécie humana. A idéia de que a obrigação moral se estende para além dessa espécie para um grupo ainda maiorse transforma na idéia de lealdade a todos aqueles que, como nós mesmos, podem sentir doraté mesmo vacas e cangurus - ou talvez mesmo a todas os seres vivos, incluindo as árvores (p.45).

Os alvos são Rawls e Habermas e suas tentativas de elaborar uma moral universalista, mesmo que dentro de um quadro não-subjetivista e pós-metafísico. Para Rorty, a noção de universalidade é dispensável - um termo que, como "verdade", é apenas uma espécie de indicação de que há um consenso, contextualizado e falível, em torno de um determinado enunciado, seja cognitivo ou normativo.

Em "Philosophy as a transitional genre", Rorty volta à noção de uma cultura pós-Filosófica e procura sugerir que, assim como o Iluminismo se desenvolveu no contexto de um processo de perda de centralidade da religião, éigualmente em um contexto de crítica à tradição da Filosofia moderna que tem se desenvolvido, nas últimas décadas, aquilo que chama de "cultura literária". Religião, Filosofia e "cultura literária" são, para Rorty, três formas distintas - e sucessivas — de vida intelectual. A vantagem da última em relação às duas primeiras consiste no abandono do desejo por uma imagem "verdadeira" (no sentido de correspondência à realidade) do mundo. A pluralidade de mundos e vidas possíveis oferecidas pela literatura dá o modelo para o tratamento, pelo intelectual, da tradição cultural moderna. Menos preocupado em descobrir a verdadeira natureza das coisas, esse intelectual prefere entrar em contato e colocar frente a frente diferentes possibilidades de explicação do mundo, de normas sociais e de formas de expressão da subjetividade e adotar aquela que lhe parecer mais adequada para os seus fins - que, idealmente, devem estarvinculados ao controle da natureza em benefício da humanidade, à construção de uma sociedade mais justa e à construção autônoma da personalidade.

Essas perspectivas de uma cultura pós-Filosófica estão relacionadas a um suposto esgotamento de debates já tradicionais dentro da tradição analítica. Em "Uma visão pragmatista da filosofia analítica contemporânea", Rorty afirma que tentativas recentes (como, por exemplo, os trabalhos de Arthur Fine) de colocar de lado os debates entre realistas e antirealistas ${ }^{8}$ - ou seja, entre os filósofos que vêem no conhecimento uma maneira de o homem entrar em contato com uma realidade independente e aqueles que, dos idealistas aos pragmatistas, dispensam essa concepção do conhecimento - indicam uma ruptura de grande alcance na tradição, significando principalmente o abandono da noção de conhecimento como representação, noção criticada por Rorty desde A filosofia e o espelho da natureza. O resultado deste abandono significaria o início de uma nova maneira de encarar a filosofia: 
Nós nos veríamos livres tanto da problemática sujeito-objeto, que tem dominado a filosofia desde Descartes, quanto da problemática aparênciarealidade que nos acompanha desde os gregos. Nós não mais nos sentiríamos tentados a praticar a epistemologia ou a ontologia (p.133).

Debates como esse são, para Rorty, o resultado de um processo de excessiva profissionalização da filosofia, que teria descaracterizado a área desde os tempos de Kant. Adotar uma visão não-representacional do conhecimento e da linguagem significaria livrar-se de Kant em favor do historicismo de Hegel. O resultado dessa mudança de paradigma, por assim dizer, redefiniria o papel do filósofo que, para Rorty - e seguindo o exemplo de um intelectual que se notabilizou por sua atuação pública e crítica diante das questões colocadas pelos desdobramentos políticos contemporâneos, da Guerra Fria ao atual governo Bush - , deveria imitar o romancista e, em vez de compreender sua atividade como a procura de soluções racionais, "científicas", de problemas filosóficos, procurar elaborar sugestões criativas para a redescrição da condição humana. Figura-chave da esfera pública moderna, o filósofo deveria deixar o isolamento tecnicista a que parte da filosofia contemporânea o condenou e ingressar nos debates coletivos em torno de direitos, valores e identidades. Sua contribuição específica seria a de quem carrega consigo uma extensa tradição, adquirida pela leitura e debate com seus colegas de profissão, de tentativas de descrição e redescrição daquilo que constituiria a "boa via" - como diriam os gregos - humana.

Apesar de rejeitar as analogias entre filosofia e ciência, Rorty deixa como legado o que poderia ser considerado um projeto de pesquisa filosófico a ser levado adiante. Os itens abaixo servem como indicação de alguns pontos fundamentais de sua obra que mereceriam uma reconsideração crítica.

Em primeiro lugar, a crítica na forma de uma narrativa das grandes imagens do mundo não consegue atribuir racionalidade à mudança na passagem de um paradigma filosófico a outro. Para Rorty, filósofos "revolucionários" (no sentido de Thomas Kuhn) "decidem" se livrar daquilo que se consolidou como discurso normal, uma vez que esses vocabulários se tornam "entediantes". Expressões como "escolher", "decidir", "se livrar de" ocupam o lugar de explicações que possam dar conta de uma reconstrução racional — ainda que comprometida pela visão em retrospecto - da história da filosofia.

Um trecho um tanto longo de "Analytic and conversational philosophy" é um bom exemplo desse tipo de reconstrução narrativa:

Hegel expressava impaciência com o vocabulário utilizado por filósofos que, como Kant, insistiam na irredutibilidade da distinção entre sujeito e 
[9] Grifos meus.

[10]Conferir, por exemplo, "Pragmatism and romanticism". In: Philosophy as cultural politics, p. 105

[11] "Habermas, Derrida and the functions of philosophy". In: Truth and progress - Philosophical papers, vol. 3. Cambridge: Cambridge University Press, 1998. objeto. Para persuadir as pessoas a parar de falar de modo cartesiano e kantiano, ele ofereceu uma redescrição total do progresso cognitivo, moral e intelectual, como de muitas outras coisas. Ele deu a muitos dos velhos termos utilizados na discussão destes assuntos sentidos novos, propriamente hegelianos. O segundo Wittgenstein expressava impaciência com o seu próprio Tractatus e com os esquemas mentais compartilhados por Moore e Russell. Austin colocou Ayer de escanteio porque ele ficou impaciente com as tentativas de seus colegas de Oxford em tentar encontrar algo digno de ser preservado no empirismo britânico. Brandom não está dizendo: todo mundo tementendido os conceitos de forma errada, e estou entendendo de forma correta. Ele está na verdade dizendo algo como:explicações representacionalistas do conteúdo semântico se tornaram familiares, e os problemas que têm despertado são cada vez mais entediantes, então vamos experimentar uma explicação inferencialista para ver se as coisas andam melhor. A fenomenologia do espírito $e$ Making it explicit, como as Investigações filosóficas e Sense and sensibilia, não são livros dos quais valha a pena perguntar 'O que eles apresentam de forma correta?' - nem mesmo 'O que eles estão tentando apresentar de forma correta?'. É mais útil perguntar: ajudar-nos-ia se começássemos a falar desta maneira? (pp.125-6)9.

Sem dúvida, há muito de retórica nesse tipo de passagem, e estudos como $A$ filosofia e o espelho da natureza apresentam análises da história da filosofia muito mais rigorosas e detalhadas. No entanto, a idéia algo romântica da atividade filosófica que Rorty propõe $e^{10}$ pode ser uma das razões por trás de sua recusa em ver essa história como um esforço coletivo e racional em direção ao refinamento de um projeto vinculado à construção de uma noção não-religiosa e não-metafísica de universalidade.

Em segundo lugar, Rorty parece escolher o caminho menos interessante que sua crítica às tentativas de cientifização da filosofia abre. Paradoxalmente, sua revisão do papel da filosofia como fundamentação do conhecimento não rompe com seu isolamento em relação às ciências humanas. Para Rorty a análise filosófica, ainda que liberada das pressões positivistas, parece bastar a si mesma. Exemplo disso é sua rejeição a projetos "construtivos", como o de Jürgen Habermas, que igualmente toma como ponto de partida a virada lingüística e realiza uma crítica semelhante a certos pressupostos da filosofia moderna, mas que procura ao mesmo tempo dar substância, por assim dizer, a essa crítica em uma teoria da ação comunicativa.

Em uma análise comparativa de Habermas e Jacques Derrida ${ }^{11}$, Rorty diz não estar de acordo com a suposta necessidade de que uma diferenciação entre usos da linguagem seja teoricamente fundamentada. Habermas vêa lguns perigos na dissolução dos limites entre teoria e narrativa proposta por Derrida — os usos poético e argumenta- 
tivo da linguagem se tornariam indistintos, o que inviabilizaria a construção de uma teoria da racionalidade comunicativa e privaria a reflexão filosófica de uma de suas funções fundamentais: a elaboração de um horizonte normativo para as práticas discursivas em torno de valores e normas, ou seja, a elaboração de critérios que permitam distinguir entre consensos que tenham sido atingidos racionalmente $e$ outros que estejam baseados no uso de influência, poder ou sejam mero interesse instrumental disfarçado. Rorty tem razão em desconfiar deversões demasiado "fundacionistas" desta distinção (ou da dissolução desta mesma distinção); mas a proposta de Habermas é mais modesta do que isso e, no lugar de uma distinção da "natureza" dessas duas formas de linguagem (poética e argumentativa), sua teoria propõe uma distinção com base em sua função (seus usos) e nos seus pressupostos implícitos. De um lado, o uso poético pressupõe liberdade de ressignificação das palavras com intenção expressiva; de outro, o uso argumentativo pressupõe o compartilhamento de significados, a capacidade de defender com razões um enunciado (cognitivo, normativo) e o compromisso de agir segundo o consenso obtido. Rorty insiste, no entanto, em que o fazer ou não essa distinção tem valor segundo o tipo de resultado que um pensador pode tirar disso; trata-se da liberdade criativa do filósofo em propor ou dissolver distinções seja para criticar a tradição ou construir o futuro. Essa saída, no entanto, priva Rorty de elementos mais consistentes para explicar o processo de mudança político-cultural: a recusa em incorporar uma teoria substantiva das práticas lingüísticas deixa em suas mãos, como explicação para essa dinâmica, a imagem de um terremoto que tem origem no seu epicentro - o gabinete do gênio filosófico - e que, por um movimento causal, atinge o entorno com seu poder destrutivo. Além desta caracterização do papel do filósofo, Rorty tem pouco mais a oferecer contra Habermas do que uma crítica que evita o enfrentamento direto e apenas reconhece no seu projeto mais uma versão de uma velha história, a do filósofo platônico que, desdenhando da contingência humana, quer enraizar sua reflexão em "algo maior" do que a história - na "Natureza humana", na "Racionalidade" etc.:

Se partimos da idéia de que a liberdade é antes o reconhecimento da contingência do que da existência de um reino especificamente humano isento da necessidade natural, teremos mais razões para desconfiar da utilidade social da filosofia do que Habermas parece ter. Esperaremos menos da filosofia, pelo menos do tipo de filosofia caracterizado por aquilo que Habermas chama "problemáticas universalistas e fortes estratégias teóricas"12.

Em terceiro e último lugar, a noção de política cultural conforme esboçada por Rorty tem poder de fogo, como elemento de transforma- 
[13] Honneth, A. Disrespect - The normative foundations of critical theory. Cambridge: Polity Press: 2007 (tradução para o inglês de Das Andere der Gerechtigkeit. Frankfurt am Main: Suhrkamp Verlag, 2000).

[14] Rorty, R. "Habermas, Derrida and the functions of philosophy". In: Truth and progress - Philosophical papers, vol.3. p.323. ção cultural, muito menor do que espera o filósofo. Sem uma teoria da transformação dessa revisão de vocabulário em um meio efetivo de coordenação das relações sociais - sem uma teoria normativa da moral e do direito, que indiquem como uma revisão das práticas lingüísticas (elaborada de forma discursiva, racional e fechada em torno de um consenso ainda que provisório), transforma-se em compromisso entre os falantes - a idéia de política cultural é inócua e aprofunda não só o isolamento da filosofia em relação às outras áreas das ciências humanas como coloca novamente o filósofo - ou o "homem de letras" - não apenas no papel de árbitro da cultura como o reveste de uma missão tão irrealista quanto aquela que Platão lhe atribui nas piores páginas da República.

Parece haver, no pensamento de Rorty, algo como um déficit sociológico. Sua noção de política cultural fica perdida em uma obra que, por menos otimista que seja, em alguns momentos, com o quadro político e social contemporâneos, oferece poucos parâmetros claros para a análise e para a crítica da sociedade moderna. Sem dúvida, Rorty contribuiu de forma decisiva para o pensamento "liberal" da segunda metade do século XX e destes primeiros e sombrios anos do século XXI, mas antes como participante do debate do que como teórico propriamente dito. Sua versão às vezes radicalizada do pragmatismo e seu historicismo o fazem recusar um elemento da crítica sociofilosófica que Axel Honneth, em "Patologias do social: o passado e presente da filosofia social"13, caracterizou como fundamental para uma teoria crítica da sociedade: uma noção (mínima, secular, normativa) de "natureza humana" a ser protegida dos entraves colocados pela vida social a sua autonomia. Para Rorty, o abandono de um ideal de validade universal em favor de uma posição historicista como a sua tornaria "impossível pensar em 'autonomia' como 'liberação de forças repressoras de origem externa' ou como 'a distorção daquilo que é essencialmente humano por instituições sociais'"14. No lugar de diagnósticos como estes, Rorty prefere afirmar a missão de intelectuais, jornalistas, artistas e escritores de identificar as práticas particulares que, no presente, geram sofrimento e privação.

Esse déficit fica mais evidente quando Rorty parece não conseguir responder de que forma essas redescrições oferecidas pelos intelectuais ganham efetividade. Que tipo de compromisso é criado depois que as metáforas introduzidas pelo filósofo se tornam conceitos corriqueiros, e aquelas criticadas ou caem em desuso ou são encaminhadas para o departamento de filologia? Esse problema poderia, eventualmente, ser contornado por uma teoria que vinculasse a contingência das formas sociais, das normas, crenças etc. à exigência de universalidade implícita nessas tentativas discursivas (e intersubjetivas) de crítica e recriação das práticas e instituições sociais. Nesse 
caso, o pensamento de Rorty talvez pudesse se beneficiar, por exemplo, da "lógica" da noção de fato social: a constatação de que a vida social constitui uma "segunda natureza" e as práticas e categorias sociais principalmente aquelas que tomam corpo pela ação institucional, como é justamente o caso de raça $a^{15}$ - geram fenômenos que se colocam no limiar entre puro fato objetivo e mera construção social. Sem serem fatos "encontrados na natureza", independentes da mente humana, não deixam de ser uma realidade que determina a ação e a interpretação dos indivíduos. Esse caráter ambíguo, por assim dizer, do fato social é análogo às constatações da análise pragmático-transcendental da interação lingüística proposta por Karl-Otto Apel e Habermas. Ambos propõem a reabilitação de noções como verdade e universalidade em um quadro não-realista, pragmático: sem serem fatos nem objetivos nem "metafísicos" - ou "transcendentais", na ortodoxia kantiana - da cognição humana, são elementos constitutivos da interação mediada pela linguagem, e, como tais, sujeitos às regras que constituem a racionalidade do procedimento argumentativo e criam as condições para o compromisso entre os falantes.

Nas palavras do próprio Habermas, o pragmatismo de Rortye a proposta de uma abordagem pragmático-transcendental seriam menos posições filosóficas incompatíveis do que versões complementares da "virada lingüística". Compartilham - e isso talvez seja mais importante do que as questões propriamente filosóficas, no sentido mais tradicional do termo - uma mesma preocupação em preservar o horizonte de racionalidade que guia o projeto filosófico moderno.

Richard Rorty morreu no dia 8 de junho de 2007 . Por mais críticas que sua obra possa despertar - e, em muitos casos, como as aqui indicadas, elas são antes complementos do que tentativas de refutação - ela não trai o compromisso de um intelectual que, na tradição secular e democrática do pragmatismo norte-americano, procurou defender e indicar os caminhos para a construção de uma sociedade em que vidas intelectuais como a sua pudessem florescer.

JOAQUIM TOLEDO JR.é mestrando no Departamento de Filosofia da FFLCH-USP e integrante do núcleo Direito e Democracia do Cebrap.
[15]Ver, por exemplo, Wacquant, Loïc. "Da escravidão ao encarceramento em massa: repensando a 'questão racial' nos Estados Unidos". In: Contragolpes — seleção de artigos da New Left Review. São Paulo: Boitempo, 2006. 
Anúncio Vetruvius 